\title{
The Investigation of Mixed Ferrofluids Containing Iron Oxide nanoparticles and Microspheres
}

\author{
Sharanabasava V. Ganachari $\left(\mathbb{D},{ }^{1,2}\right.$ Veerabhadragouda B. Patil $\mathbb{D}^{3},^{3}$ \\ Nagaraj R. Banapurmath $\mathbb{D},{ }^{2}$ Manzoore Elahi M. Soudagar $\mathbb{D}^{4},{ }^{4}$ Kiran Shahapurkar $\left(\mathbb{D},{ }^{5}\right.$ \\ Ashraf Elfasakhany, ${ }^{6}$ Mishal Alsehli, ${ }^{6}$ Akshata Yavagal, ${ }^{2}$ Pradyumna Mogre, ${ }^{2}$ \\ Vijayakumar M Hiremath, ${ }^{7}$ and Shankar A. Hallad ${ }^{2}$ \\ ${ }^{1}$ Department of Chemistry, School of Advanced Sciences, KLE Technological University BVB Campus Vidyanagar, \\ Hubballi-80031, Karnataka, India \\ ${ }^{2}$ Centre for Material Science, School of Mechanical Engineering, KLE Technological University BVB Campus Vidyanagar, \\ Hubballi-80031, Karnataka, India \\ ${ }^{3}$ Institute of Energetic Materials, Faculty of Chemical Technology, University of Pardubice, Studentska 95, Pardubice 53210, \\ Czech Republic \\ ${ }^{4}$ Department of Mechanical Engineering, School of Technology, Glocal University, Delhi-Yamunotri Marg, SH - 57, \\ Mirzapur Pole, Saharanpur District, Uttar Pradesh-247121, India \\ ${ }^{5}$ School of Mechanical, Chemical and Materials Engineering, Adama Science and Technology University, Adama 1888, Ethiopia \\ ${ }^{6}$ Mechanical Engineering Department, College of Engineering, Taif University, P.O. Box 11099, Taif 21944, Saudi Arabia \\ ${ }^{7}$ Centre for Nanotechnology, Department of Processing and Food Engineering, CAE, UAS, Raichur 584104, Karnataka, India
}

Correspondence should be addressed to Kiran Shahapurkar; kiranhs1588@astu.edu.et

Received 19 September 2021; Revised 29 October 2021; Accepted 23 November 2021; Published 9 December 2021

Academic Editor: Ali Khorram

Copyright (C) 2021 Sharanabasava V. Ganachari et al. This is an open access article distributed under the Creative Commons Attribution License, which permits unrestricted use, distribution, and reproduction in any medium, provided the original work is properly cited.

\begin{abstract}
The aim of the present work is the synthesis and characterization of iron oxide $\left(\mathrm{Fe}_{3} \mathrm{O}_{4}\right)$ nanoparticles. These nanoparticles are coated with oleic acid and polyvinyl butyral and mixed with microspheres and further developed ferrofluids with silicon oil. Studies of the performance of the nanoparticles in these ferrofluids with and without coating agents were carried out. The nanoparticles were synthesized using the chemical co-precipitation technique and coated with oleic acid and polyvinyl butyral, and it further mixed with microsphere ferrofluids and developed using silicon oil. The prepared $\mathrm{Fe}_{3} \mathrm{O}_{4}$ nanoparticles and their coated forms of oleic acid and polyvinyl butyral were mixed with microspheres; furthermore, ferrofluids were developed with silicon oil. All forms of these ferrofluids are characterized for morphology and phase purity (SEM, XRD, and FTIR). The iron oxide $\left(\mathrm{Fe}_{3} \mathrm{O}_{4}\right)$ nanoparticles have shown different magnetic properties, differentiating macroscopic iron oxide in suspended particles. The ratio of surface to volume increases along with the decrease in atomic size, essential for assessing the surface morphological properties. The magneto-rheological (MR) fluids were determined, and shear stress of Expancel microsphere mixed iron oxide nanoparticle with and without them was found almost equal. However, the ferrofluid with PVB coated nanoparticles and microspheres emerged as a stable rheological ferrofluid, sustaining high shear stress and low viscosity with increasing shear rate. Also, shear rates up to $650 \mathrm{~s}^{-1}$ have been observed, showing very high shear stress withstanding capacity. The stability and performance of the magnetic colloidal ferrofluids depend on the thermal contribution and the balance between attractive/ repulsive interactions.
\end{abstract}

\section{Introduction}

The rheological materials exhibit their properties instantly when subjected to variation of stimulus. These materials are electro-sensitive and magneto-sensitive, varying based on the materials state, whether solid, liquid, or gaseous. Researchers are working on modifications of magneto-rheological materials and their reactivity on the applied electric field [1-3]. These magneto-rheological materials are sensitive to small voltages and provide stimuli in the shortest 
time. Usually, these materials exist in a suspension, mainly in watery fluid or oils with iron particles suspended in the media possessing an active magnetic nature $[4,5]$. At the molecular level, the magnetic moment exists due to electrons partially filling/electron delocalization in the 3D [Fe] orbital. Researchers have predicted that a magnetic effect in materials such as iron aligns to an axis of the applied magnetic field vector. The magnetic effect changes the state of the nanoparticles by changing their entropy. The material attains a solid state after the molecules are aligned to postmagnetic field applications [6-8].

MR fluids are colloidal ferromagnetic (FM) particles with a size ranging from 1 to $20 \mu \mathrm{m}$ in a transporter liquid, which does not show any characteristic magnetic properties. A portion of FM particles in an MR fluid ranges from 10 to $15 \%$ in quantity. These particles are generally synthesized from iron or iron oxides, cobalt, or nickel alloys [9-12]. The saturation magnetization of the material is around $2.2 \mathrm{~T}$. The transporter liquid depends on the projecting application conditions of MR liquids (fluids). Most extensively used carrier fluids incorporate mineral or synthetic oils. Some of them are based on water, polyesters, or polyether. MR liquids may include adjuvants to prevent settling and assemblage of particles, increase their lubricity characteristics, and minimize these effects; SWCNT (single-walled carbon nanotubes) are incorporated in the CI-based MR fluid. There are some other combinations also available, primarily surfactants, which are added to increase fluid permanence. These incorporate polymers or carboxyl acids, and some with an inedible vegetable oil such as Honge (Millettia pinnata) oil as a transporter kind of liquids were used as fluid content, and only $25 \mathrm{kPa}$ of yield stress has been generated [12-16]. The CI particles encapsulated with polymethyl methacrylate as core-shell designed particles enhanced the rinsing properties of the MR fluid. Wire-like iron nanostructures were applied to the standard MR fluid based on $\mathrm{CI}$, and a form of dimorphous MR fluid was synthesized. For use in high-performance engineering, high yield stress and colloid distribution highly influence MR fluid performance. Among several magnetic materials, a primeval carbonyl iron (CI) has been extensively studied as an MR material for MR characteristics due to its high magnetic field strength properties. However, the CI-based MR suspensions have been identified to possess some disadvantages, for example, dispersion of sedimentation and nonuniformity of CI particles due to a significant difference in density [12-16]. However, to avoid this, dispersants in MR fluids were designed to increase dispersal constancy [17]. In other cases, magnetic particles coated with polymer cores or monodispersed polymer cores treated with magnetic particles enable a lower density of magnetic particles [18].

The iron nanoparticles have different magnetic properties, differentiating them from macroscopic iron in suspended particles. Their surface-to-volume ratio increases and reduces atomic size, so the surface properties are important for using any nanomaterial $[19,20]$. It is also dependent on the ratio which is considered to be the function of size. Therefore, smaller size influences surface properties, interface properties, agglomeration of the particles, and physical properties of the material [21, 22]. For better consistency and longevity of the material, the nanosized iron is used to minimize the in-use thickening effect caused in macrosize particles [21]. The magnetic materials have been used in various applications in medical science, e.g., magnetic resonance imaging (MRI), sustained transfer of drugs to appropriate target organs/cells, cell isolation, biofluid detoxification, tissue repair, and hyperthermia. These magnetic nanoparticles show super paramagnetism phenomena and do not retain magnetism after the supply of the magnetic field, which offers the advantage of particle aggregation [18, 23-26]. The magnetic particles derived from magnetic transition metals (iron, nickel, and cobalt) are readily oxidized, whereas the iron oxide-like magnetite $\left(\mathrm{Fe}_{3} \mathrm{O}_{4}\right)$ form is more stable against oxidation. These particles of nanomagnetite exhibit very strong ferri-magnetic behaviour and are less susceptible to oxidation. The iron oxide particles are highly condensed since they belong to nontoxic materials and are biologically consistent [27, 28].

Magnetic properties of the materials depend on the atomic radius of the nanoparticle synthesized along with the presence of ionic species with their ratios. The average diameter of the atoms ranges between $0.05 \mu \mathrm{M}$ and $0.1 \mathrm{nM}$, which can be obtained by varying the experimental conditions (mainly environmental factors such as humidity, room temperature, and atmospheric pressures). However, the system is always polydispersed in size due to larger nanoparticles that grow at the cost of smaller nanoparticles [29]. Improvement in synthetic methods will obtain the size of the nanoparticles of the desired dimension. The uniform particles are typically prepared to separate nucleation and nuclei growth through a homogeneous precipitation reaction [30].

Synthesis and application of magneto-rheological fluid have been interesting studies from the past couple of decades $[11,25,31,32]$. The main rise in this area is because of its impressive change in viscosity property under the applied magnetic field (Bingham plasticity). It has ability to turn a normal fluid-containing metal (iron) into a semisolid-like material, with various applications primarily in the automobile industry for the suspension system, braking system, etc. In the suspension system, the MR fluid is used to automatically adjust the stability of the car according to the road. Typically, MR fluid synthesis contains a $0.35-0.49$ volume fraction of pure iron particles with nearly a spheroidal form, and size is usually of the range $1-8 \mathrm{~nm}$. Also, the density has variations in the range $7-8 \mathrm{gm} / \mathrm{cm}^{3}$. This property influences fair shear stress and a good off-state viscosity [19, 33-36].

As the magnetic field increases, viscosity changes along with yield strength but not to its full potential when it absorbs shock [37]. With iron being a dense particle, it easily agglomerates at the bottom, making it hard to redistribute. Many organic materials have been used before to protect the iron from rusting and avoid agglomeration [38]. A few study areas where advanced nanomaterials are critical include functionalized nanoparticles, polymers and nanocomposites, energetic materials and multifunctional materials, drug-delivery and tissue engineering, and bio-inspired and hybrid nanomaterials. [39-46]. 
The paper proposes numerous methods to obtain effective MR fluid for suspension purposes with higher damping properties for a longer period. The nanoiron is coated with surfactant PVB (polyvinyl butyral) and microsphere is added in the carrier fluid as a separate entity. The microspheres address increasing of the stress withstanding capacity of the MR fluids, whereas PVB avoids agglomeration and prevents rusting.

\section{Materials}

The primary materials, used along with the iron particles which also form aspects in deciding its efficiency, were polyvinyl butyral $\left[\left(\mathrm{C}_{8} \mathrm{H}_{14} \mathrm{O}_{2}\right)_{n}\right]$, microspheres DET, oleic acid, and silicon oil. All the materials were procured from Sigma Aldrich from a regional retailer.

2.1. Polyvinyl Butyral $\left[\left(\mathrm{C}_{8} \mathrm{H}_{14} \mathrm{O}_{2}\right)_{n}\right]$. The polyvinyl butyral) (PVB) is consisting of reactive, markedly hydrophobic (water-hating), and hydrophilic (water-loving) polymer units. The hydrophobic group has good thermoplastic processability and solubility in the solvent. The hydrophilic group has high adhesion to inorganic material (in this case, iron particles).

2.2. Microspheres DET. Expancel microspheres 909 DET $80 \mathrm{~d}$ 40: its main property expands when external pressure is applied and returns to the original volume as the load is removed. The expanded microspheres are easy to compress, and it is made of 2 shells one covering the other; the inner shell can blow when pressure is applied.

\section{Methods}

The preparation is split into mainly three categories as preparation of nanoiron, coating with oleic acid as the surfactant, and coating with polymer PVB as the surfactant.

3.1. Preparation of Fe-Nanoparticle. Synthesis of nanoiron directly affects properties (magnetism, sedimentation, viscosity, etc., of the iron, in which the MR fluid comprising of $\mathrm{Fe}_{3} \mathrm{O}_{4}$ nanoparticles is developed by the chemical co-precipitation method used for the synthesis of iron Fe (III) (ferric) and iron Fe (II) (ferrous) salts in the alkaline medium which is known as Reimer's procedure. Preparation of $\mathrm{Fe}_{3} \mathrm{O}_{4}$ nanoparticles is done by adding two equivalents of $\mathrm{FeCl}_{2} \cdot 4 \mathrm{H}_{2} \mathrm{O}$ and three equivalents of, $\mathrm{FeCl}_{3} \cdot 6 \mathrm{H}_{2} \mathrm{O}$ in $500 \mathrm{ml}$ of distilled waters; then, ammonium solution is added to it. The precipitate was filtered and then dried at $120^{\circ} \mathrm{C}$, grinded by mortar-pestle, and characterized. The flow diagram of the chemical co-precipitation method is shown in Figure 1.

3.2. $\mathrm{Fe}_{3} \mathrm{O}_{4}$-Coated Nanoparticles with Oleic Acid. Prepared $10 \mathrm{gms}$ of nanoiron was added to $100 \mathrm{ml}$ diluted ammonium hydroxide such that $\mathrm{pH} 9$ is obtained and $0.77 \%$ weight percentage of oleic acid solution is added to it; sonication is carried out at $353 \mathrm{~K}$, after which dilute nitric acid is added dropwise so that $\mathrm{pH} 5$ is obtained. The precipitate settles down; this residue was washed with water and acetone to remove the no-reacted oleic acid.

3.3. $\mathrm{Fe}_{2} \mathrm{O}_{3}$-Coated Nanoparticles with $\mathrm{PVB} .5 \mathrm{~g}$ of $\mathrm{PVB}$ is dissolved in $100 \mathrm{ml}$ of chloroform; in the other beaker, nanoiron $5 \mathrm{gm}$, SDS $2 \mathrm{gm}$, and $3 \mathrm{gm}$ of a triblock copolymer were mixed into $400 \mathrm{ml}$ of water. The whole was kept under $720 \mathrm{rpm}$ for 4 hours and later for chloroform evaporation for two days. Subsequently, the precipitate was washed with distilled water and kept for drying. Table 1 shows the composition of the samples prepared.

For detailed understanding, the influence of each additive on the performance of ferrofluid composed mixtures for the study was prepared as mentioned in Table 1 .

\section{Characterizations}

The characterization of the obtained samples was carried out using SEM coupled EDAX Model-JEOI-SEM 6360 with a high resolution of $3.0 \mathrm{~nm}$ at $30 \mathrm{kV}$ and X-ray diffraction Phillips 3710 (wide angle powder X-ray diffractometer) in the $2 \theta$ range $10^{\circ}$ to $100^{\circ}$ using $\mathrm{CuK} \alpha 1$ radiation source $(\lambda=1.54056 \AA)$, at Shivaji University Kolhapur (SUK). FTIR spectrophotometer $4000 \mathrm{~cm}^{-1}$ to $450 \mathrm{~cm}^{-1}$ for spectral studies of the chemical bonds present in compounds was ascertained using Perkin Elmer spectrum one undertaken at Karnataka University, Dharwad (KUD). The analysis of the results is presented in the following section.

The rheological properties were ascertained at Indian Institute of Science (IISc), Bangalore. The discovery hybrid rheometer is a rotational shear rheometer with various measurement preferences that include viscosity, shear stress, storage and loss modulus, strain, and phase angle. The geometries available include a $40 \mathrm{~mm}$ parallel plate, 25 and $40 \mathrm{~mm} 2^{\circ}$ angle, and cup rotor with options of a vaned and conical rotor. It has three heating system options, a Peltier plate, Peltier concentric cylinders, and an environmental test chamber. The viscosity, shear rate, and shear stress were ascertained here using the above-specified equation.

\section{Results and Discussion}

5.1. Scanning Electron Microscopy (SEM). There were large agglomerates formed and found in the sample of range $100 \mathrm{~nm}$. It is seen from the images that range from $\mathrm{Fe}_{3} \mathrm{O}_{4}$ lied in between 10 and $75 \mathrm{~nm}$ Figure 2(a); oleic acid-coated nanoiron comes to be around $210 \mathrm{~nm}$ (Figure 2(b)); PVB coated image (Figure 2(c)) has maximum size which obtained $217 \mathrm{~nm}$ as per addition of less amount of PVB which was used for coating.

The nanoparticles in the sample have flakes-like structures, implying that the nanomaterial has characteristic properties of iron. Sample 1(b) containing oleic acid has obtained the striations at higher resolution, and sample 1(c) has obtained small thin-sized irregular-shaped particles, implying the copolymer present in the sample. Here, the agglomeration of particles was more widespread because of which the clusters of the compound are formed. 


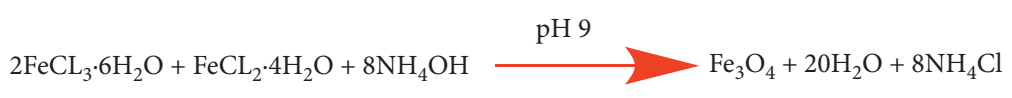

(a) mixing of anionic \& cationic solutions

(b)

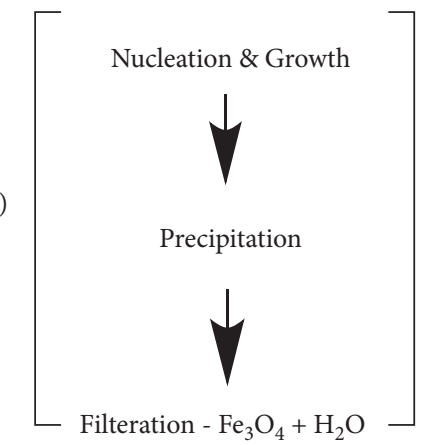

(c) Calcination (at $\left.120^{\circ} \mathrm{C}\right)-\mathrm{Fe}_{3} \mathrm{O}_{4}$

(d) Modified Ferrofluids -MRF1; MRF2; MRF3 MRF4 \& MRF (b)

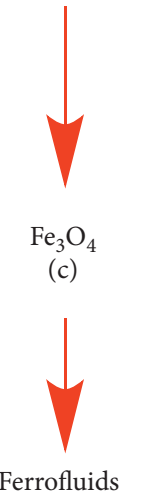

(d)

Figure 1: Flow diagram of the chemical co-precipitation method.

5.2. Fourier Transform Infrared Spectroscopy (FTIR). In the $\mathrm{Fe}_{3} \mathrm{O}_{4}$ graph, peaks around $600-400 \mathrm{~cm}^{-1}$ are assigned the $\mathrm{Fe}-\mathrm{O}$ stretching; $516 \mathrm{~cm}^{-1}, 632 \mathrm{~cm}^{-1}$, and $552 \mathrm{~cm}^{-1}$ show the presence of the $\mathrm{Fe}-\mathrm{O}$ bond. The peak gets reduced for the coated nanoiron in spectra which confirm the presence of polymer at the surface and iron nanoparticles at core shell. In the spectrum of $\mathrm{PVB}+$ nano $\mathrm{Fe}_{3} \mathrm{O}_{4}, \mathrm{O}-\mathrm{H}$ stretching is at $3437 \mathrm{~cm}^{-1}$ and also $1108 \mathrm{~cm}^{-1}$ peaks, which show $\mathrm{C}-\mathrm{O}-\mathrm{C}$ bond; stretching is more regarding $\mathrm{PVB}$ coated. The sample containing oleic acid has shown wavelengths of $750-800 \mathrm{~cm}^{-1}$, which indicates the organic bonds, especially $\mathrm{C}=\mathrm{O}$ bonds bending in the compound, i.e., ferric oxide coated with oleic acid particles and the composite of ferric oxide-PVB. In contrast with the pure ferric oxide particles, the distinctive vibrations of the ferric oxide coating are visible at the wavenumbers of about $700-500 \mathrm{~cm}^{-1}$ and $1060 \mathrm{~cm}^{-1}$ endorsed to $\mathrm{C}-\mathrm{O}$, $\mathrm{C}=\mathrm{O}$, and $\mathrm{C}-\mathrm{N}$ bonds, respectively. The typical vibrations of PVB are detected at $1650 \mathrm{~cm}^{-1}$, and series from approximately $1250 \mathrm{~cm}^{-1}$ to $700 \mathrm{~cm}^{-1}$ indicates the carbonyl groups and also $\mathrm{C}-\mathrm{H}, \mathrm{C}-\mathrm{C}$, and $\mathrm{C}-\mathrm{O}$ bonds of the structure, respectively. At high wavenumbers (above $3400 \mathrm{~cm}^{1}$ ), the distinctive elongating from the hydroxyl groups are marginally observed.

With the interaction of the $\mathrm{Fe}_{3} \mathrm{O}_{4}$ coating with the PVB, the variances between the spectra are minor. A substantial lengthening is detected in $2600-3500 \mathrm{~cm}^{-1}$. In this range, the specific stretching vibrations from the free hydroxyl groups are like what is visible in $\mathrm{PVB}$, as it contains $\mathrm{O}-\mathrm{H}$ groups. These interpretations could be suggestions of hydrogen bonding through the $\mathrm{O}-\mathrm{H}$ groups from Figure 3.
5.3. Powder X-Ray Diffraction (XRD) Studies. The XRD patterns of the composite showed distinct peaks at $2 \theta$ values of $30.1,34.5,37.1,57.1$, and 62.6, which correspond to the characteristic peaks of $\mathrm{Fe}_{3} \mathrm{O}_{4}$ (JCPDS card number 19-0629) [18]. The results obtained for the ferric oxide are within its standard, and other compounds also tend to form the same. We can observe that the material in both ferric oxides with PVB and oleic acid tends to have disorders or the entropy change is similar due to the re-crystallization of the agglomerated particles. The improper re-crystallization is seen more in ferric oxide native form rather than as suspended particulate in other compounds. The improper re-crystallization tells us the state of the substance, as neither solid nor liquid it is analogous to jelly, but it is a suspension of magneto-rheological material.

The geometry of the material cannot be ascertained here in a distorted form of the state of the material. The size of the particles can be established with precision using Bragg's law, and the particle size ranges from 4 to $10 \AA$ for the three samples for their corresponding peaks of the $2 \theta$ shown in Figure 4 .

5.4. Rheological Studies. The graphs in Figures 5 and 6 and Table 2 show the rheological parameters' variation of the samples prepared based on the indentation carried out. The samples were tested for five different current values for 310 seconds each, the stable one was extracted, and the shear rate vs. shear stress was plotted in Figure 5; similarly, viscosity vs. shear rate was also plotted in Figure 6. The graphs indicate the oleic acid does not significantly influence shear stress 
Table 1: Composition and designation of samples.

\begin{tabular}{llc}
\hline Sl. No's & Codes & Components \\
\hline 1 & MRF1 & Silicon oil + oleic acid-coated iron oxide (Fe3O4) nanoparticles \\
2 & MRF2 & Silicon oil + oleic acid-coated iron oxide (Fe3O4) nanoparticles + microspheres \\
3 & MRF3 & Silicon oil + PVB coated iron oxide (Fe3O4) nanoparticles \\
4 & MRF4 & Silicon oil + PVB coated iron oxide (Fe3O4) nanoparticles microspheres \\
5 & MRF5 & Silicon oil + microsphere \\
\hline
\end{tabular}

(a)

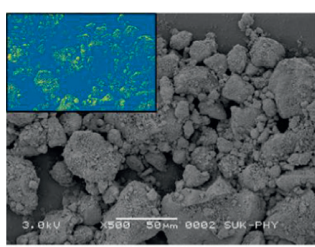

(b)

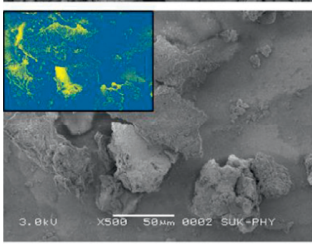

(c)

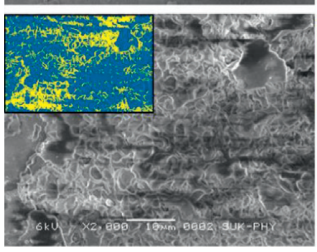

(i)
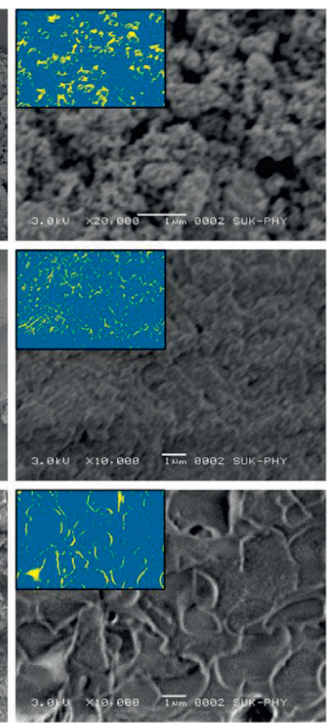

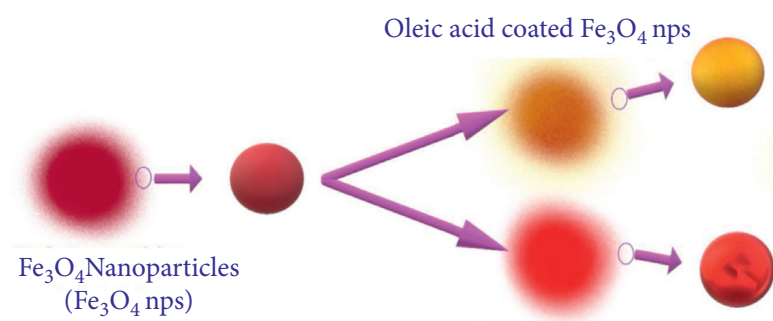

PVB coated $\mathrm{Fe}_{3} \mathrm{O}_{4}$ nps

$\left(\mathrm{Fe}_{3} \mathrm{O}_{4} \mathrm{nps}\right)$

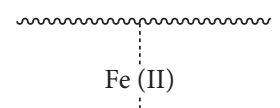

me (II)
:

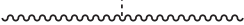

ms - (a), (b) and (c)

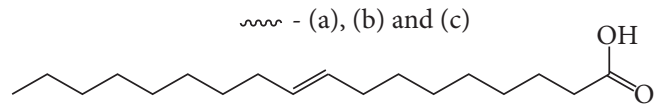

(a) Oleic acid

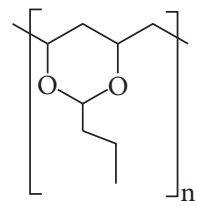

(b) poly vinyl butyral

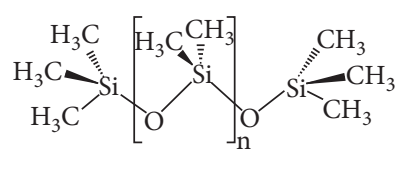

(c) polydimethylsiloxane

(iii)

Figure 2: (a): SEM images of (A) iron oxide $\left(\mathrm{Fe}_{3} \mathrm{O}_{4}\right)$ particles slightly agglomerated, (B) oleic acid-coated $\mathrm{Fe}_{3} \mathrm{O}_{4}$, and (C) PVB-coated Fe $\mathrm{O}_{4}$ particles separated with gaining smoother surface. (b) Schematic representation of the coating with a zoomed view of a single particle. Oleic acid coating attains Fe nanoparticles to yellow-brownish coloration, whereas PVB gives glassy surface to the particles; it can be seen clearly in the SEM (C) images also. (c) Schematic representation of molecular interaction of Fe nanoparticles with a polymeric moiety.

compared to PVB. It looks like the shear stress of PVB coated nanoiron with microsphere is approximately the same as PVB coated nanoiron but showed very high shear stress withstanding capacity at $650 \mathrm{~s}^{-1}$ shear rates. However, the MRF4 showed a more linear stable and sustained shear strain compared to MRF3. It indicates that PVB and microspheres making iron nanoparticles maintain regular shear strain.
Similarly, in the case of viscosity variation to shear rate, MRF4 has a comparable viscosity to MRF3 but is very high compared to oleic acid coating. It indicates the significant influence of microspheres, and PVB makes easy flow by maintaining the high shear stress and decreasing viscosity with increasing shear rate. The microspheres have a very low density and do not settle down quickly. It clears that iron oxide nanoparticles' ferrofluid mixed with microspheres and 


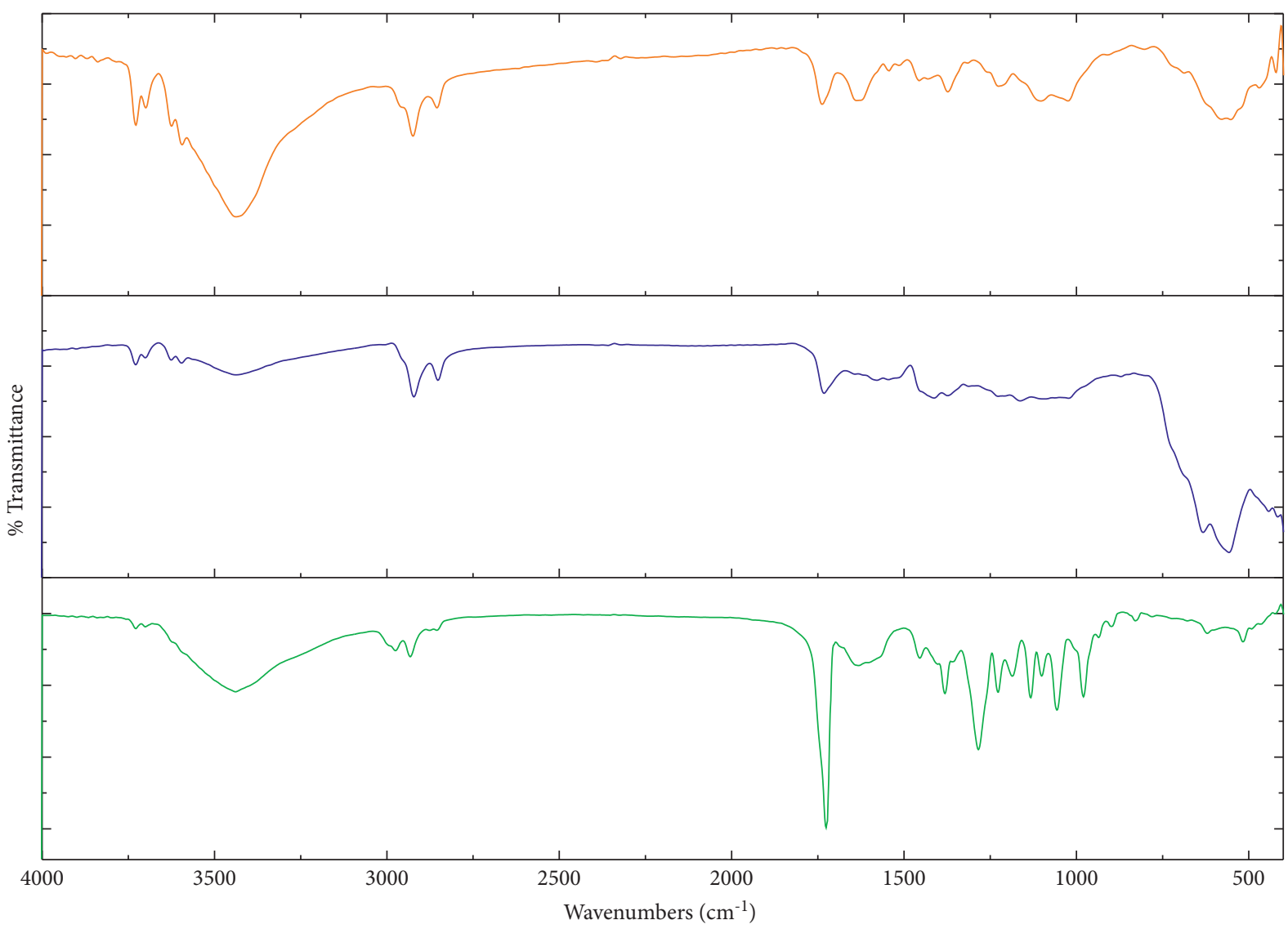

$-\mathrm{Fe}_{3} \mathrm{O}_{4}+\mathrm{PVB}$
$-\mathrm{Fe}_{3} \mathrm{O}_{4}+$ oleic acid
$-\mathrm{Fe}_{3} \mathrm{O}_{4}$

FIGURE 3: FTIR spectrum of all the forms of $\mathrm{Fe}_{3} \mathrm{O}_{4}$ nanoparticles. 


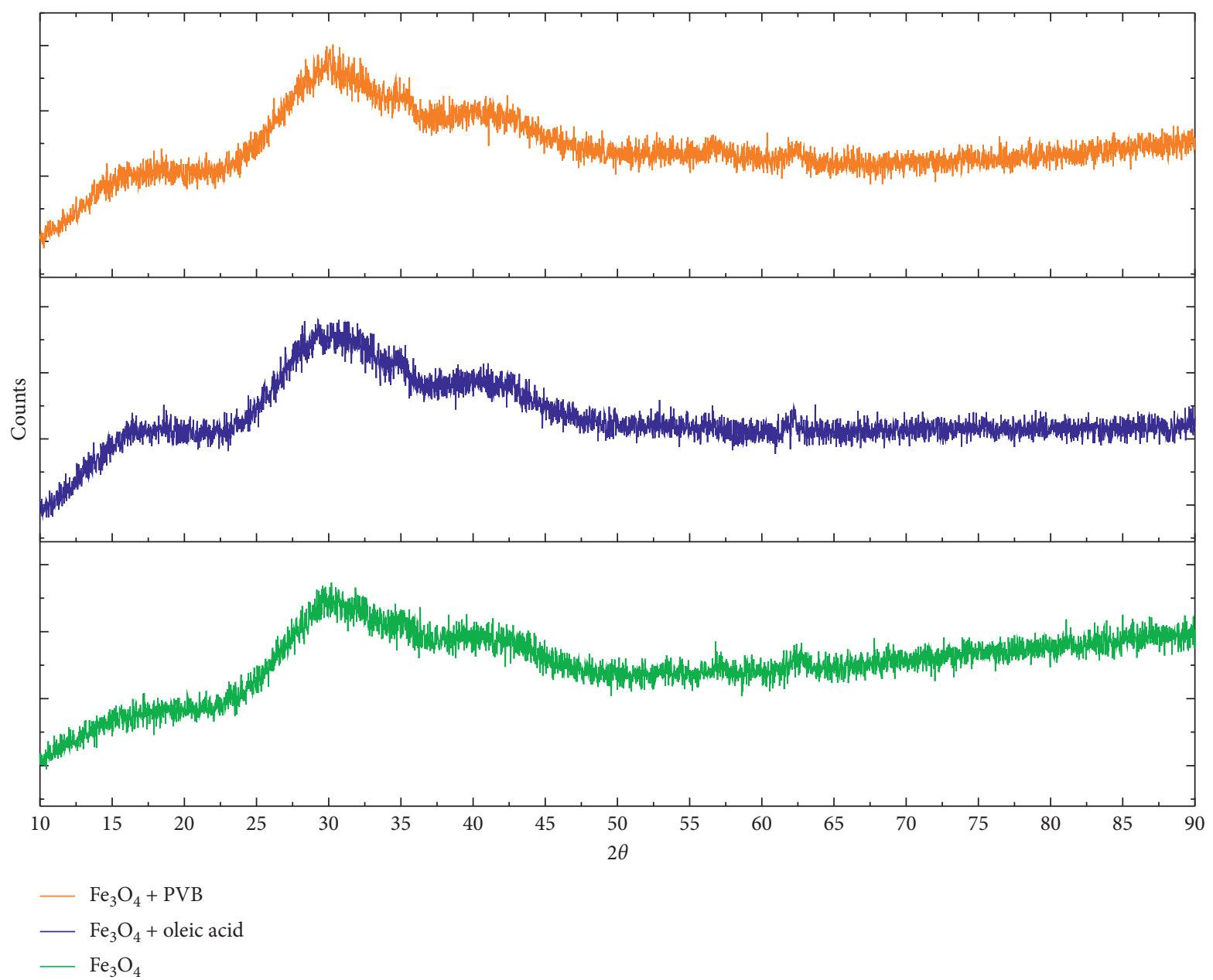

FIgURE 4: X-ray diffraction pattern of all the forms of $\mathrm{Fe}_{3} \mathrm{O}_{4}$ nanoparticles. 


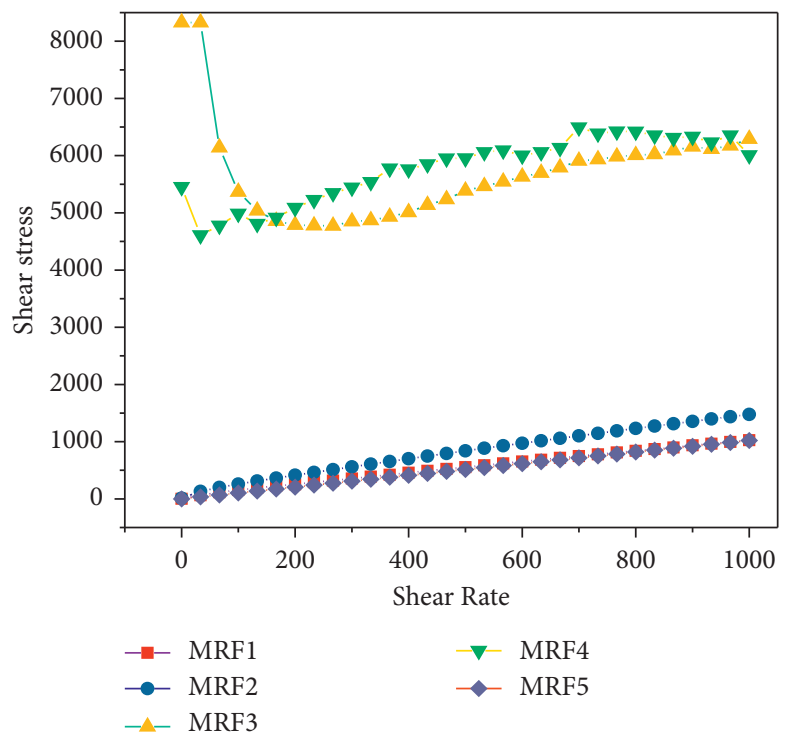

FIGURE 5: Shear rate vs. shear stress for MRFs.

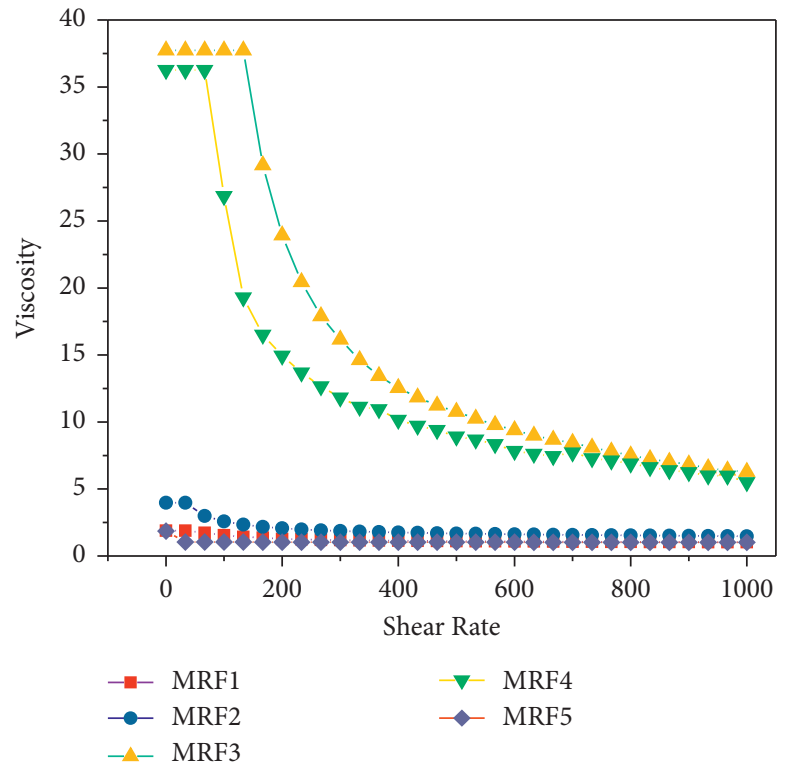

Figure 6: Shear rate vs. viscosity for MRFs.

TABLE 2: Rheological properties of synthesized ferrofluids.

Shear stress Viscosity 
PVB are very good for the application point of view, requiring stable shear strain and low viscosity.

\section{Conclusion}

The novel idea of adding the microsphere and coating polymer over the nanoiron in magneto-rheological fluids increases its load damping capacity and improves the life of nanoiron used. When scheming with new polymer nanocomposites, the following feature should be considered: sizedependent material characteristics of the nanoparticles used and the reproducibility of properties Particle conglomeration effect of adjuvants such as surfactants, plasticizing agents, and others on the composite characteristics. The highest approachable shear forces throughout compounding affect composite properties.

The precipitation technique used produced particle size maintaining in the nanorange to obtain the higher optimum values of iron in the material. PVB-coated iron shows similar magnetism when compared to normal oleic acid-coated molecules. The density of PVB is less, so they exhibit less agglomeration and help the iron from not getting oxidized under any other external environmental factors and enhance the rheological performance of ferrofluid. The stabilizers assist in maintaining the particles' colloidal in the liquid. When the magnetic particle is adsorbed on the outside to increase polarization, the surfactants activate the colloidal particles until the magnetic field requirement is met. The microsphere having the property of expansion and reduction of size is being used efficiently in the above-concluded experimentation. These ferrofluids can be used in futuristic applications such as rotating shaft motors and loudspeakers to dampen vibrations, etc. [47].

\section{Data Availability}

Data are available on request via mail to the corresponding author.

\section{Conflicts of Interest}

The authors declare no conflicts of interest.

\section{Acknowledgments}

The authors S. V. Ganachari and N. R. Banapurmath are thankful to KLE Society Belagavi and KLE Technological University (formerly known as B. V. Bhoomaraddi College of Engineering and Technology) for supporting this research. This research work was also supported by B. V. Bhoomaraddi College of Engineering and Technology under "Capacity Building Projects" (Principal Investigator Dr. Sharanabasava V. Ganachari). This work was supported by Taif University researchers supporting project number (TURSP-2020/205), Taif University, Taif, Saudi Arabia.

\section{References}

[1] J. Bajkowski, J. Nachman, M. Shillor, and M. Sofonea, "A model for a magnetorheological damper," Mathematical and Computer Modelling, vol. 48, no. 1-2, pp. 56-68, 2008.

[2] S. Odenbach, T. Rylewicz, and M. Heyen, "A rheometer dedicated for the investigation of viscoelastic effects in commercial magnetic fluids," Journal of Magnetism and Magnetic Materials, vol. 201, no. 1-3, pp. 155-158, 1999.

[3] K. Shahrivar, A. L. Ortiz, and J. De Vicente, "A comparative study of the tribological performance of ferrofluids and magnetorheological fluids within steel-steel point contacts," Tribology International, vol. 78, pp. 125-133, 2014.

[4] G. Bossis, S. Cutillas, E. Lemaire, A. Meunier, and O. Volkova, "Adaptative fluids: rheology and light transmission control," in Proceedings of the 3rd International Conference on Intelligent Materials and 3rd European Conference on Smart Structures and Materials, F.P. Gobin Pierre and J. Tatibouet, Eds., pp. 306-309, Lyon, France, June 1996.

[5] J. A. Miranda, R. M. Oliveira, and D. P. Jackson, "Adhesion phenomena in ferrofluids," E Statistical Nonlinear Soft Matter Physics, vol. 70, no. 3, pp. 036311-36410, 2004.

[6] J. Nowak and S. Odenbach, "A capillary viscometer designed for the characterization of biocompatible ferrofluids," Journal of Magnetism and Magnetic Materials, vol. 411, pp. 49-54, 2016.

[7] M. Martsenyuk, "A dissipative process in ferrofluid in nonhomogeneous magnetic field," IEEE Transactions on Magnetics, vol. 16, no. 2, pp. 298-300, 1980.

[8] J. Nowak, D. Wolf, and S. Odenbach, "A rheological and microscopical characterization of biocompatible ferrofluids," Journal of Magnetism and Magnetic Materials, vol. 354, pp. 98-104, 2014.

[9] C. C. Ekwebelam and H. See, "Determining the flow curves for an inverse ferrofluid," Korea-Australia Rheol. J, vol. 20, no. 1, pp. $35-42,2008$.

[10] M. T. López-López, A. Gómez-Ramírez, L. Rodríguez-Arco, J. D. G. Durán, L. Iskakova, and A. Zubarev, "Colloids on the Frontier of ferrofluids. Rheological properties," Langmuir, vol. 28, no. 15, pp. 6232-6245, 2012.

[11] J. R. Morillas, E. Carreón-González, and J. De Vicente, "Effect of particle aspect ratio in magnetorheology," Smart Material Structure, vol. 24, no. 12, 2015.

[12] D. Susan-Resiga and L. Vékás, "Ferrofluid based composite fluids: magnetorheological properties correlated by Mason and Casson numbers," Journal of Rheology, vol. 61, no. 3, pp. 401-408, 2017.

[13] S. Masoud Hosseini, L. Vafajoo, E. Ghasemi, and B. H. Salman, "Experimental investigation the effect of nanoparticle concentration on the rheological behavior of paraffin-based nickel ferrofluid," International Journal of Heat and Mass Transfer, vol. 93, pp. 228-234, 2016.

[14] Y. Cheng, D. Li, and R. Dai, "Experimental analysis of starting torque of perfluoro polyethers-based magnetic fluid seal," Harbin Gongcheng Daxue XuebaoJournal Harbin Eng Univ, vol. 38, no. 8, pp. 1316-1321, 2017.

[15] K. Shahrivar and J. De Vicente, "Ferrofluid lubrication of compliant polymeric contacts: effect of non-homogeneous magnetic fields," Tribology Letters, vol. 56, no. 2, pp. 281-292, 2014.

[16] P. Ilg and S. Odenbach, Ferrofluid structure and rheology, Springer-Verlag, Berlin, Germany, 2009. 
[17] Z. Laherisheth and R. V. Upadhyay, "Influence of particle shape on the magnetic and steady shear magneto-rheological properties of nanoparticle based MR fluids," Smart Material Structures, vol. 26, no. 5, 2017.

[18] R. Y. Hong, T. T. Pan, Y. P. Han, H. Z. Li, J. Ding, and S. Han, "Magnetic field synthesis of $\mathrm{Fe} 3 \mathrm{O} 4$ nanoparticles used as a precursor of ferrofluids," Journal of Magnetism and Magnetic Materials, vol. 310, no. 1, pp. 37-47, 2007.

[19] G. Bossis and E. Lemaire, "Yield stresses in magnetic suspensions," Journal of Rheology, vol. 35, no. 7, pp. 1345-1354, 1991.

[20] A. Fazlali, S. Lashkarara, and A. H. Mohammadi, "Rheological properties of paraffin-based co3O4 nano-ferrofluid," $A d v$ Nanotechnol, pp. 169-181, Nova Science Publishers, Inc., New York NY USA, 2014.

[21] L. M. Armijo, L. A. Ahuré-Powell, and N. M. Wereley, "Rheological characterization of a magneto-rheological ferrofluid using iron nitride nanoparticles," Journal Applied Physics, vol. 117, 2015.

[22] D. Borin, A. Zubarev, D. Chirikov, R. Müller, and S. Odenbach, "Ferrofluid with clustered iron nanoparticles: slow relaxation of rheological properties under joint action of shear flow and magnetic field," Journal of Magnetism and Magnetic Materials, vol. 323, no. 10, pp. 1273-1277, 2011.

[23] C. Rinaldi, A. Chaves, S. Elborai, X. He, and M. Zahn, "Magnetic fluid rheology and flows," Current Opinion in Colloid \& Interface Science, vol. 10, no. 3-4, pp. 141-157, 2005.

[24] S. Thurm and S. Odenbach, "Magnetic separation of ferrofluids," Journal of Magnetism and Magnetic Materials, vol. 252, pp. 247-249, 2002.

[25] M. Timko, A. Zentko, M. Zentkova et al., "Magnetorheological properties of some ferrofluids," IEEE Transactions on Magnetics, vol. 30, no. 2, pp. 1117-1119, 1994.

[26] C. Rinaldi, "Magneto-rheological measurements in suspensions of magnetic nanoparticles," in Proceedings of the ASME 2005 International Mechanical Engineering Congress and Exposition, vol. 1086, Orlando, FL, USA, November 2005.

[27] M. M. Rahman and A. Venkataraman, "Synthsesis of $\gamma$-Fe2O3 by thermal decomposition of ferrous gluconate dihydrate," Journal of Thermal Analysis and Calorimetry, vol. 68, no. 1, pp. 91-101, 2002.

[28] M. Nedyalkova, B. Donkova, J. Romanova, G. Tzvetkov, S. Madurga, and V. Simeonov, "Iron oxide nanoparticles - in vivo/in vitro biomedical applications and in silico studies," Advances in Colloid and Interface Science, vol. 249, pp. 192212, 2017.

[29] C. N. R. Rao, "Raman spectra OF complex metal oxides," Indian Journal Pure Applied Physics, vol. 16, pp. 277-281, 1978.

[30] C. N. R. Rao, "Chemical approaches to the design of oxide materials," Pure and Applied Chemistry, vol. 66, no. 9, pp. 1765-1772, 1994.

[31] E. Ghasemi, A. Mirhabibi, and M. Edrissi, "Magnetoviscous effect in a maghemite ferrofluid," Journal of Nanoscience and Nanotechnology, vol. 11, no. 6, pp. 5285-5291, 2011.

[32] R. Mahesh, R. Mahendiran, A. K. Raychaudhuri, and C. N. R. Rao, "Effect of the internal pressure due to the A-site cations on the giant magnetoresistance and related properties of doped rare earth manganates, $\ln 1$-xAxMnO3 $(\ln =\mathrm{La}, \mathrm{Nd}$, Gd, Y; A = Ca, Sr, Ba, Pb)," Journal of Solid State Chemistry, vol. 120, no. 1, pp. 204-207, 1995.
[33] K. Shah, S.-B. Choi, and H. Jin Choi, "Thermorheological properties of nano-magnetorheological fluid in dynamic mode: experimental investigation," Smart Material. Structures, vol. 24, 2015.

[34] C. C. Ekwebelam and H. See, "Using oscillatory shear to probe the effects of bidispersity in inverse ferrofluids," Korea Aust. Rheol. J, vol. 19, pp. 35-42, 2007.

[35] M. Chand, S. Kumar, A. Shankar, R. Porwal, and R. P. Pant, "The size induced effect on rheological properties of Co-ferrite based ferrofluid," Journal of Non-crystalline Solids, vol. 361, pp. 38-42, 2013.

[36] G. Bossis, E. Lemaire, O. Volkova, and H. Clercx, "Yield stress in magnetorheological and electrorheological fluids: a comparison between microscopic and macroscopic structural models," Journal of Rheology, vol. 41, no. 3, pp. 687-704, 1997.

[37] K. Vasu, H. S. S. R. Matte, S. N. Shirodkar et al., "Effect of high-temperature shock-wave compression on few-layer MoS2, WS2 and MoSe2," Chemical Physics Letters, vol. 582, pp. 105-109, 2013.

[38] S. V. Ganachari, V. K. Joshi, R. Bhat, R. Deshpande, B. Salimath, and N. V. S. Rao, "Large scale synthesis and characterization of $\gamma$ - $\mathrm{Fe} 2 \mathrm{O} 3$ nanoparticles by self-propagating low temperature combustion method," International Journal Science Research, vol. 1, no. 2, pp. 77-79, 2012.

[39] S. Sagar Iqbal, B. Ali, N. Hossain et al., "Synergetic influence of F-MWCNTS on polyvinylpyrrolidone sodium alginate composite membrane for reverse osmosis," Journal of Environmental Chemical Engineering, vol. 9, no. 5, Article ID 106085, 2021.

[40] S. V. Ganachari, L. R. Viannie, P. Mogre, R. P. Tapaskar, and J. S. Yaradoddi, L. Martínez, O. Kharissova, and B. Kharisov, "Conducting polymer composite-based sensors for flexible electronics," in Handbook of Ecomaterials, Springer, New York, NY, USA, 2019.

[41] S. Ali Mazari, N. Hossain, W. Jeffrey Basirun et al., "An overview of catalytic conversion of $\mathrm{CO} 2$ into fuels and chemicals using metal organic frameworks," Process Safety and Environmental Protection, vol. 149, pp. 67-92, 2021.

[42] S. A Mazari, R. Abro, and F. S. A. Khan, "Nanomaterials: Applications, waste-handling, environmental toxicities, and future challenges-a review," Journal of Environmental Chemical Engineering, vol. 9, no. Issue 2, Article ID 105028, 2021.

[43] K. R. Sanadi, P. D. Sanadi, M. L. Gaur, A. V. Mali, and G. S. Kamble, "Optical, electrical and morphological studies of $\beta \mathrm{HgS}$ thin film prepared by improved chemical bath deposition technique," Bulletin of Materials Science, vol. 44, no. 1, 42 pages, 2021.

[44] V. B. Patil, K. Zalewski, J. Schuster, P. Bělina, W. A. Trzciński, and S. Zeman, "A new insight into the energetic co-agglomerate structures of attractive nitramines," Chemical Engineering Journal, vol. 420, no. 3, Article ID 130472, 2021.

[45] K. C. Rathod, P. D. Kamble, K. R. Sanadi, G. S. Kamble, M. L. Guar, and K. M. Garadkar, "Photovoltaic application study of zinc telluride thin films grown by chemical bath deposition method," Advances in Materials Physics and Chemistry, vol. 11, no. 8, pp. 131-144, 2021.

[46] M. T. H. Siddiqui, H. Ahmed Baloch, S. Nizamuddin et al., "Synthesis and optimization of chitosan supported magnetic carbon bio-nanocomposites and bio-oil production by solvothermal carbonization co-precipitation for advanced 
energy applications," Renewable Energy, vol. 178, pp. 587-599, 2021.

[47] V. Nimbagal, N. R. Banapurmath, A. M. Sajjan, A. Y. Patil, and S. V. Ganachari, "Studies on hybrid bio-nanocomposites for structural applications," Journal of Materials Engineering and Performance, vol. 30, no. 9, pp. 6461-6480, 2021. 